Temporal var $i$ at $i$ ons of accumul at ed cesi um in nat ural soi Is after an unchar acteristic external exposure

\begin{tabular}{|l|l|}
\hline 著者 & $\begin{array}{l}\text { Sawai H kar u, Rahman I snai I M M, Lu Chao, } \\
\text { Tsukagoshi Yoshi nor i , Begum Zi nnat A. , Naki } \\
\text { Ter uya, Hasegawa Hi r oshi }\end{array}$ \\
\hline $\begin{array}{l}\text { j our nal or } \\
\text { publ i cat i on ti t l e }\end{array}$ & M cr ochem cal J our nal \\
\hline vol une & 118 \\
\hline page r ange & 158 165 \\
\hline year & 2014 12-01 \\
\hline URL & ht t p: //hdl . handl e. net /2297/40163 \\
\hline
\end{tabular}


The research article is originally published at Microchemical Journal An Elsevier Journal

http://www.journals.elsevier.com/microchemical-journal/

The original publication is available at: http://dx.doi.org/10.1016/j.microc.2014.09.006

\section{Temporal Variations of Accumulated Cesium in Natural Soils after an Uncharacteristic External Exposure}

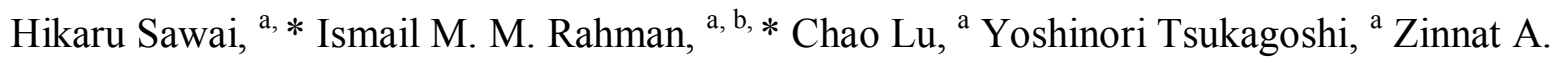
Begum, ${ }^{\mathrm{a}}$ Teruya Maki, ${ }^{\mathrm{c}}$ Hiroshi Hasegawa ${ }^{\mathrm{c}, *}$

${ }^{a}$ Graduate School of Natural Science and Technology, Kanazawa University, Kakuma, Kanazawa 920-1192, Japan

${ }^{\mathrm{b}}$ Department of Applied and Environmental Chemistry, Faculty of Science, University of Chittagong, Chittagong 4331, Bangladesh

${ }^{\mathrm{c}}$ Institute of Science and Engineering, Kanazawa University, Kakuma, Kanazawa 920-1192, Japan

*Author(s) for correspondence

E-mail: hikaru.sawai@gmail.com (HS); I.M.M.Rahman@gmail.com (I.M.M.R.);

hhiroshi@se.kanazawa-u.ac.jp (H.H.)

TEL/Fax: +81-76-234-4792

Please Cite the article as: H. Sawai, I.M.M. Rahman, C. Lu, Y. Tsukagoshi, Z.A. Begum, T. Maki and $\mathrm{H}$. Hasegawa, Temporal variations of accumulated cesium in natural soils after an uncharacteristic external exposure, Microchemical Journal, 118: 158-165, 2015. 


\begin{abstract}
The accumulation behaviors and solid phase partitioning patterns of stable cesium, which have been recognized as an indicator of the long-term movement of radioactive cesium $\left({ }^{137} \mathrm{Cs}\right.$ or $\left.{ }^{134} \mathrm{Cs}\right)$ in ecosystems, were studied in typical and natural soils of Japanese origin, namely, red clay, leaf-mold and andosol soils. The retention and migration of soil-phase cesium have been explained relative to various factors, such as soil organic matter contents, competitive cation concentrations and the adsorption ratio of $\mathrm{Cs}$ to the solid phase. Cesium was adsorbed nearly quantitatively in the leaf-mold type soil, and the rate of Cs absorption increased as the particle size decreased in the red clay and andosol soils. The distributions of Cs within the soil solid phases were defined using the selective sequential extraction scheme and were used to explain its relative incorporation in the soil fractions. Solid phase fractionation indicated that nearly half of the total cesium concentrations in the soils were in the 'residual' fraction (representing the metal that was incorporated within the crystalline lattice of the soil and was difficult to extract). These findings are expected to provide information regarding suitable conditions for remediation, immobilization or the recovery of cesium from contaminated soils with excess cesium concentrations.
\end{abstract}

\title{
Keywords
}

Cesium; Accidental exposure; Soil contamination; Solid-phase distribution; Sequential fractionation; Temporal variation 


\subsection{Introduction}

Waste disposal operations or accidental releases due to nuclear-technology-related activities have resulted in the release of large amounts of radionuclides into the environment. The accidental release of radionuclides has been a topic of interest for years, beginning with the catastrophic nuclear accident that occurred on 26 April 1986 at the Chernobyl Nuclear Power Plant [1, 2]. The Fukushima Dai-ichi Nuclear Power Plant (FDNPP) accident that resulted from an earthquake and subsequent tsunami on March 11, 2011 is the most recent example of such a catastrophe. Following the FDNPP accident, a large number $(\sim 500)$ of studies were published that covered the various aspects of the accident. Sorting these published articles by topic in the ISI-listed journals indicated that the studies mainly focused on radioactivity monitoring in places with foods. This trend becomes obvious when considering the importance of estimating the effects of fallout on human health. Approximately $80 \%$ of the FDNPP-generated fallout in the contamination zone affected agriculture, including forests [3]. However, very few publications have discussed the effects of fallout on agriculture, including soil contamination due to the extended radionuclide emissions [4-7].

Among the radioactive materials, the dispersion of radiocesium at elevated concentrations evokes concern due to its extended solubility characteristics as an alkaline metal ion, its comparatively longer half-life, and its easy incorporation into living beings [810]. The most notable radiocesium isotope is ${ }^{137} \mathrm{Cs}$, which has a half-life of 30.2 years [11], is abundant in nuclear wastes and in radioactive fallout and can contaminate large areas of agricultural land [12-15]. The FDNPP accident resulted in an estimated atmospheric release of $1.3 \times 10^{16} \mathrm{~Bq}$ of ${ }^{137} \mathrm{Cs}$ over four weeks (March 12 and April 6, 2011) [16]. Approximately $10-20 \%$ of the emitted radiocesium was deposited over the terrestrial soils in northeastern Japan $[15,17]$. The accumulated radiocesium in soils is a threat because plants can take up Cs [18]. Thus, it is important to understand the accumulation and dissemination patterns of radiocesium in the soil to assess the potential health risks of Cs contamination or its impacts on food production after over-exposure occurs. Moreover, radiocesium (particularly ${ }^{137} \mathrm{Cs}$ ) is 
extremely useful for quantifying soil erosion and deposition risks in forested and agricultural areas where knowledge regarding diffusion processes is important $[19,20]$.

The fate of radiocesium in the environment and its subsequent migration in soils depends on its physico-chemical form and commonly follows the behavior of its stable form $[9,21,22]$. For example, previous research indicated that the soil-to-plant transfer factor of ${ }^{137} \mathrm{Cs}$ follows a pattern that is similar to stable Cs [22-26]. In addition, analogous distributions of ${ }^{137} \mathrm{Cs}$ have been observed in different rice components relative to stable ${ }^{133} \mathrm{Cs}$ species $[27,28]$.

The objective of this study is to investigate the cesium distribution in the operationally defined physico-chemical and particle size fractions of soils to understand the temporal variations of cesium after being released at an uncharacteristic rate.

\subsection{Experimental}

\subsection{Instruments}

The atomic absorption spectroscopy (AAS) technique was used to determine the stable cesium concentration in solution. An AAnalyst 600 (PerkinElmer, Waltham, MA) was used that was equipped with a transverse heated graphite atomizer with an integrated, pyrolytic graphite coated platform and a longitudinal Zeeman-effect background corrector. The light source was an electrodeless discharge lamp (EDL) that was powered by an EDL System II that was operated at $18 \mathrm{~mA}$. The wavelength was set at the $852.1 \mathrm{~nm}$ resonance line and the monochromator spectral bandpass was set at $0.7 \mathrm{~nm}$. In addition, a baseline offset correction time at $2.0 \mathrm{~s}$ was used with a read delay of $0.0 \mathrm{~s}$. Argon was used as the purge gas at a flow of $250 \mathrm{~mL} \mathrm{~min}^{-1}$. The temperature sequence was 110 (drying), 130 (drying), 750 (ashing) and $1900{ }^{\circ} \mathrm{C}$ (atomization), which were performed for 30, 30, 20 and $4 \mathrm{~s}$, respectively. The loading volume was $20 \mu \mathrm{L}$, with $20 \mu \mathrm{L}$ of the sample and matrix-modifier $\left(1 \% \mathrm{H}_{2} \mathrm{SO}_{4}\right)$. Calibration was conducted thereby using three standard solutions that contained $0.01,0.05$ and $0.1 \mathrm{mg} \mathrm{L}^{-1}$ cesium.

Inductively coupled plasma optical emission spectrometry (ICP-OES) was used to detect the co-existing trace metals (e.g., Al, Ca, Fe, K, Mg, Mn and $\mathrm{Na}$ ) in solution. For this 
analysis, an iCAP 6300 instrument from Thermo Fisher Scientific (Waltham, MA) was used that included an EMT duo quartz torch, a glass spray chamber and a concentric glass nebulizer. A radio frequency power of $1.15 \mathrm{~kW}$ was used at the torch, the plasma, auxiliary and nebulizer gas flows were maintained at 12,1 and $0.5 \mathrm{~L} \mathrm{~min}^{-1}$, respectively, and an integration time of $30 \mathrm{~s}$ was used.

The microwave-assisted reaction was used to digest the soil samples. For this analysis, a Multiwave 3000 instrument from Anton Paar GmbH (Graz, Austria) was used that was equipped with an 8-position rotor and hydraulic pressurized sensing system for all vessels. The vessels (XF100) supported a controlled pressure of $6 \mathrm{MPa}$, a maximum operating pressure of $12 \mathrm{MPa}$ and a maximum temperature of $240{ }^{\circ} \mathrm{C}$.

A KDF S-8 muffle furnace from Kenis Scientific (Osaka, Japan), a Digiprep Jr block heater from SCP Science (Quebec, Canada) and a DX 600 oven from Yamato Scientific (Tokyo, Japan) were used for heating or drying.

Ultrapure water with a resistivity $>18.2 \mathrm{M} \Omega \cdot \mathrm{cm}$ was prepared using the Arium Pro UV water purification system from Sartorius Stedim Biotech GmbH (Göttingen, Germany). The pH measurements were performed using a Navi F-52 pH meter from Horiba Instruments (Kyoto, Japan).

Each instrumental measurement or treatment procedure was performed in three replicates and the resulting averaged value is reported.

\subsection{Materials}

\subsubsection{Soil samples}

The soil samples represented three soil types that are common in most regions of Japan (including the Fukushima), red clay, leaf-mold and andosol soils. A large amount (approximately $5 \mathrm{~kg}$ ) of each soil type was collected from representative locations in Kanazawa, which is located on the Sea of Japan and is bordered by the Japanese Alps. The soil samples were dried for $24 \mathrm{~h}$ at $60{ }^{\circ} \mathrm{C}$ before separating into size fractions of 2000-212 $\mu \mathrm{m}$ (coarse sand; SF-1), 212-63 $\mu \mathrm{m}$ (fine sand; SF-2), and $<63 \mu \mathrm{m}$ (silt and clay; SF-3) with the use of grading sieves based on the ISO 14688-1 classification of soils [29]. 


\subsubsection{Chemicals and laboratory wares}

Analytical grade commercial products were used throughout the study. Cesium nitrate salt and the standard cesium solution (as $\mathrm{CsCl}$ ) were obtained from Kanto Chemical (Tokyo, Japan) and were used to prepare the working standards. In addition, the $\mathrm{HF}, \mathrm{HNO}_{3}, \mathrm{H}_{2} \mathrm{SO}_{4}$, $\mathrm{HCl}$ and $\mathrm{NaOH}$ were obtained from Kanto Chemical (Tokyo, Japan) and were used for the decomposition experiments or as mentioned below. Magnesium chloride from Merck KGaA (Darmstadt, Germany), acetic acid from Tama Chemicals (Kanagawa, Japan), hydroxylamine chloride from Wako Pure Chemical (Osaka, Japan), and hydrogen peroxide from Kanto Chemical (Tokyo, Japan) were used during the extraction experiments. The $\mathrm{HCl}$ and $\mathrm{NaOH}$ solutions $\left(1 \mathrm{~mol} \mathrm{~L}^{-1}\right)$ were used to adjust the solution $\mathrm{pH}$. Working solutions were prepared from the stock solutions by diluting with ultrapure water on a weight basis.

Low-density polyethylene (PE) bottles from Nalge Nunc (Rochester, NY), screwcapped PE tubes from AS ONE (Osaka, Japan), conical polypropylene centrifuge tubes (Biologix Research, Lenexa, KS), and micropipette tips from Nichiryo (Tokyo, Japan) were used throughout the study. The laboratory equipment was washed by soaking in Scat 20X-PF alkaline detergent from Nacalai Tesque (Kyoto, Japan) overnight and then overnight in 4 mol $\mathrm{L}^{-1} \mathrm{HCl}$ before rinsing with ultrapure water after each step.

\subsection{Methods}

\subsubsection{Preparation of Cs-contaminated soil samples}

The granulometric fractions of the dried soils $(3 \mathrm{~g})$ were spiked with $30 \mathrm{~mL}$ of a standard solution containing $5 \mathrm{mg} \mathrm{L}^{-1}$ cesium (as $\mathrm{CsCl}$ ). The soil-solution mixtures were continuously shaken in an end-over-end shaker at $200 \mathrm{rpm}$ at $25^{\circ} \mathrm{C}$ for $24 \mathrm{~h}$. During this step, the soil particles were completely and evenly exposed to the added cesium. Next, the suspension was centrifuged at $13000 \mathrm{rpm}$ for $30 \mathrm{~min}$ to separate the soil solids from the solution using a CR20GIII high-speed refrigerated centrifuge from Hitachi (Tokyo, Japan). The supernatant liquid was carefully separated and analyzed for Cs to calculate the amount of adsorbed $\mathrm{Cs}$ in the soil. The residual soil solid fraction was rinsed with the ultrapure water (5 $\mathrm{mL} \times 5)$ and then dried in an oven at $60{ }^{\circ} \mathrm{C}$ for $3 \mathrm{~h}$. The dried Cs-spiked samples were stored 
in capped bottles and were stored in the dark at $25{ }^{\circ} \mathrm{C}$ until further experiments were conducted.

\subsubsection{Determination of the total organic matter content in the raw soils}

For all of the soil types, $1 \mathrm{~g}$ from each of the segregated fractions was dried at $110 \pm 5$ ${ }^{\circ} \mathrm{C}$ in an oven for $1 \mathrm{~h}$ before subjecting the samples to a calcination treatment at $650 \pm 50{ }^{\circ} \mathrm{C}$ for $2 \mathrm{~h}$ in a muffle furnace with an air atmosphere. Next, the ash was cooled and measured to determine the weight loss from the initial value, which indicated the total organic matter content.

\subsubsection{Determination of the cation contents in the raw soil}

The soil size fractions $(0.25 \mathrm{~g})$ were placed in pre-cleaned PTFE vessels in a microwave reaction system with a mixture of $\mathrm{HNO}_{3}\left(16 \mathrm{~mol} \mathrm{~L}^{-1}, 2.5 \mathrm{~mL}\right), \mathrm{HCl}(12 \mathrm{~mol} \mathrm{~L}-1,1 \mathrm{~mL})$ and

HF (28 mol L $\left.\mathrm{L}^{-1}, 1.5 \mathrm{~mL}\right)$. The following operating conditions were used: a maximum unpulsed microwave power of $\left(P_{\max }\right)=1400 \mathrm{~W}$; a ramp time of $\left(R_{\mathrm{T}}\right)=5 \mathrm{~min}$; a hold time of $\left(H_{\mathrm{T}}\right)=35 \mathrm{~min}$ at maximum power; and a vent time of $\left(V_{\mathrm{T}}\right)=20 \mathrm{~min}$. The soil-liquid suspensions from the digestion procedure were filtered using cellulose membrane filters with a pore size of $0.45 \mu \mathrm{m}$ from Advantec (Tokyo, Japan). Next, the filtrate was evaporated on a block heater assembly at $60{ }^{\circ} \mathrm{C}$ until the total volume was reduced to a few milliliters. Next, the concentrated solution were diluted to a volume of $50 \mathrm{~mL}$ using ultrapure water and were analyzed for their total $\mathrm{Al}, \mathrm{Ca}, \mathrm{Fe}, \mathrm{K}, \mathrm{Mg}, \mathrm{Mn}$ and $\mathrm{Na}$ contents using ICP-OES.

\subsubsection{Mapping of the solid-phase cesium distributions in the soil}

The selective sequential extraction (SSE) scheme, which was originally proposed by Tessier, et al. [30], was used to map the mobility and distribution of cesium in the soilsolid phase. The scheme was based on washing the target soil sample with a series of gradually aggressive extractants [30-32]. The soil cesium was divided into five different fractions, exchangeable, acid soluble or bound to carbonates, reducible or bound to iron and manganese oxides, oxidisable or bound to the organic matter, and residual. The compositions of the extractants that were used to delineate the distinctive operationally defined fractions 
are shown in Table 1. Hereafter, the fractions are referred to as F1, F2, F3, F4 and F5, respectively.

\subsubsection{Determination of the soil cesium contents}

The pre-cleaned PTFE vessels of the microwave reaction assembly were fed with $0.25 \mathrm{~g}$ of the raw, Cs-spiked, and SSE scheme residue soils before the sequential addition of $14 \mathrm{~mol}$ $\mathrm{L}^{-1} \mathrm{HNO}_{3}(1 \mathrm{~mL}), 12 \mathrm{~mol} \mathrm{~L} \mathrm{~L}^{-1} \mathrm{HCl}(1 \mathrm{~mL})$ and $28 \mathrm{~mol} \mathrm{~L} \mathrm{~L}^{-1} \mathrm{HF}(1 \mathrm{~mL})$. The acid decomposition was concluded using a three-step microwave-assisted reaction. The first and second steps were conducted consecutively under the following conditions: (a) $P_{\max }=500 \mathrm{~W}$, $R_{\mathrm{T}}=10 \mathrm{~min}$, and $H_{\mathrm{T}}=15 \mathrm{~min}$; and (b) $P_{\max }=1400 \mathrm{~W}, R_{\mathrm{T}}=10 \mathrm{~min}, H_{\mathrm{T}}=60 \mathrm{~min}$, and $V_{\mathrm{T}}=$ $15 \mathrm{~min}$. In the third step, $5 \% \mathrm{H}_{3} \mathrm{BO}_{3}(10 \mathrm{~mL})$ was added to the soil-acid mixture under the following conditions: $P_{\max }=1400 \mathrm{~W} ; R_{\mathrm{T}}=0 \mathrm{~min} ; H_{\mathrm{T}}=15 \mathrm{~min}$; and $V_{\mathrm{T}}=15 \mathrm{~min}$. The threestep processes ensured the complete dissolution of the soil solids. The remaining solution from the PTFE vessel was carefully collected, diluted to $50 \mathrm{~mL}$ using ultrapure water, and analyzed for total Cs using GF-AAS.

\subsection{Results and discussion}

\subsection{Effects of soil type and soil particle size on the Cs assimilation in the soils}

The natural concentrations $\left(\mathrm{mg} \mathrm{kg}^{-1}\right)$ of stable cesium $\left({ }^{133} \mathrm{Cs}\right)$ in the leaf-mold, andosol and red clay soil types were $27.9 \pm 3.2,23.0 \pm 1.4$, and $6.5 \pm 1.3$, respectively (Figure 1). These values corresponded to the estimated cesium concentrations in natural soils of between 0 to $26 \mathrm{mg} \mathrm{kg}^{-1}$ [8]. The natural cesium concentrations in the red clay soil occurred in the finer particle size fraction (i.e., silt and clay; SF-3). In contrast, for the leaf-mold and andosol soil types, the distribution was uniform with 7 to $11 \mathrm{mg} \mathrm{kg}^{-1}$ of cesium in all of the soil size fractions, including the coarse sand (SF-1) and fine sand (SF-2) fractions. The ${ }^{133} \mathrm{Cs}$ distribution patterns and the size fractions of the red clay soils agree with previous findings regarding radiocesium, which indicated that the ${ }^{137} \mathrm{Cs}$ contents in the soil samples were associated with the finer size fractions and exhibited greater activities in the finer size fractions than in the bulk samples $[9,33,34]$. The adsorbed cesium concentrations $\left(\mathrm{mg} \mathrm{kg}^{-1}\right)$ were $103 \pm 2.5,116 \pm 3.9$ and $121 \pm 5.4$ in the leaf-mold, andosol and red clay soils, 
respectively, when atypically exposure occurred from an external source. In addition, the adsorption data indicated the possibility of higher cesium retention rates in the red clay soil under sudden extreme exposures relative to the other soil types. However, irrespective of the soil type, the total cesium content within the soil particle size fractions was more or less even and was in the range of 40 to $48 \mathrm{mg} \mathrm{kg}^{-1}$ (Figure 1). This pseudo-uniformity in the cesium distribution in the soil particle size fractions can be attributed to the shorter time-lag between the exposure period and concentration measurements [35]. The particle size can contribute to several effects when ${ }^{137} \mathrm{Cs}$ is used to estimate soil erosion rates. Furthermore, the particle size effects can be accounted for by using conversion models. However, these effects were not evident in other studies. If no apparent enrichment is detected in soils that were exposed to high activities, a particle size correction may not be needed for the conversion models [20, 36-39].

\subsection{Effects of soil organic matter contents on Cs assimilation in soils}

The adsorption of cesium in soils decreases as the amount of soil organic matter increases, which implies that cesium is more available to biological systems in soils with high organic matter contents $[40,41]$. This hypothesis is somewhat supported from the lowest adsorption ratio of cesium in the leaf-mold soil. The leaf-mold soil type is defined by humus or compost that consists of decomposed leaves and other organic materials. A gradual increase in the soil organic matter content was observed among the coarse sand (SF-1), fine sand (SF-2), and silt and clay (SF-3) size fractions (Figure 2a). However, the relationship between the soil cesium content $\left(\mathrm{mg} \mathrm{kg}^{-1}\right)$ and the organic matter (\%) is rather discrete (Figure 2b).

\subsection{Effects of coexisting cation concentrations on Cs assimilation in soils}

The interactions of metal cations with mineral surfaces in and near hazardous chemicals and radioactive waste sites often control the mobility of alkali metals and their radioisotopes $[42,43]$. The Al, Ca, Fe, K, Mg, Mn and Na concentrations in raw soils have been measured in different soil size fractions (Figure 3 ). In each soil type, a greater $\mathrm{K}^{+}$concentration was observed in the coarse sand fraction, while the $\mathrm{Ca}^{2+}$ and $\mathrm{Mg}^{2+}$ contents were higher in the fine 
sand fractions. The $\mathrm{Na}^{+}$ion contents were comparatively lower in the different Japanese soil types, and the distribution patterns in the different size fractions were similar to those of $\mathrm{K}^{+}$.

The sorption of cations in soil depends on ion-exchange processes, while the selectivity and fixation of the cations depend on the respective hydration energies. Cations with low hydration energies, such as $\mathrm{K}^{+}$, are fixed in the interlayers of the soil particles and are attributed to interlayer dehydration and layer collapse. In contrast, cations with high hydration energies (e.g., $\mathrm{Ca}^{2+}$, and $\mathrm{Mg}^{2+}$ ) create expanded interlayers and are not fixed [4446]. Furthermore, the $\mathrm{Cs}^{+}$cation has a low hydration energy, and the selection of $\mathrm{Cs}^{+}$over $\mathrm{Ca}^{2+}$ and $\mathrm{Na}^{+}$ions have been reported in soils [45-47]. The differences in the $\mathrm{Ca}^{2+}, \mathrm{Mg}^{2+}$ and $\mathrm{Na}^{+}$ion fixation patterns relative to $\mathrm{K}^{+}$within the soil interlayers indicate that $\mathrm{K}^{+}$may negatively influence $\mathrm{Cs}^{+}$retention patterns in the soils.

The soil $\mathrm{Al}^{3+}$ concentrations were larger than the concentrations of other ions. In addition, the $\mathrm{Fe}^{3+}$ concentration was moderate, and the $\mathrm{Mn}^{+}$concentrations were insignificant for all of the soil types. The cations with low hydration energies were retained more strongly and were interstratified regularly, likely due to the oxidation of Fe ions within the soil layers [48]. In addition, the $\mathrm{Al}^{3+}$ or $\mathrm{Fe}^{3+}$ coatings on the soil particles resulted in higher cation sorption [49]. Thus, stronger $\mathrm{Cs}^{+}$retention was expected on the red clay, leaf-mold and andosol soils. Furthermore, the combined $\mathrm{Al}^{3+}$ and $\mathrm{Fe}^{3+}$ concentrations were much higher than the $\mathrm{K}^{+}$concentrations in each soil type and soil size fraction, which likely suppressed any retention or hindering impacts.

\subsection{The distribution of solid-phase Cs in soils: Similarities between ${ }^{133} \mathrm{Cs}$ and ${ }^{137} \mathrm{Cs}$}

The SSE scheme uses several extracting solutions in sequence, and the varying reactivities and behaviors of the soil-bound metals toward the extracting solutions are correlated with the metal partitioning within the solid phases of the soils [50]. The operationally defined fractionation of ${ }^{133} \mathrm{Cs}$ in the Cs-loaded Japanese soils and the impacts of the Cs distributions over 6 months are shown in Figure 4.

The SSE treatment revealed that $90,83.7$ and $84.9 \%$ of the Cs contents in the red clay, leaf-mold and andosol soils, respectively, were incorporated in the non-detrital fractions during the earlier stages of exposure, while residual fraction contents varied from 10 to $16 \%$ 
(Figure 4a). The cumulative Cs contents in the exchangeable (F1), acid-soluble (F2), reducible (F3) and oxidisable (F4) fractions represented the 'non-detrital' fraction with mobile characteristics. The Cs fraction that was incorporated within the crystalline lattice of the soil with persistent environmental interactions was associated with the residual fraction (F5) $[32,51-53]$. The temporal Cs-distribution data indicated a common trend of decreasing Cs concentrations in the F1 fraction. However, the incorporation gradually increased in the F5 fraction. The negative variations of the F5 Cs content after one month of exposure were deliberately ignored because the period was too short to result in any convincing movement patterns within the soil phases. After 5 months, the Cs concentration in the F2 fraction increased, while the Cs concentrations in the F3 and F4 fractions decreased (Figure 4a). A similar temporal trend was observed for the different soil size fractions, regardless of the soil type (Figure 4b). The Cs concentrations in the different size fractions decreased in descending order in the leaf-mold and andosol soils and were greater in the B size fraction of the red clay soils. The data patterns from the soil size fractions indicated that the increases in the F2 and F5 Cs contents with time were not correlated with the decreasing Cs contents of the particular solid phase Cs contents (F1, F3 or F4). In addition, a mutual internal suppleness could be a more acceptable assumption for interpreting this behavior.

The metal loading in the soils due to anthropogenic affects were limited to the ionic forms or sorbed metals. However, the metals may also exist in their particulate or low solubility forms [54-57], and a random distribution of particles that are rich in metals may appear in the soil rather than the sorbed state. Sequential extraction methods have often been used to evaluate the bioavailability and mobility of radionuclides in soils based on the distribution of the physico-chemical forms of radiocesium. The solid-phase fractionation patterns of ${ }^{133} \mathrm{Cs}$-loaded and simulated Japanese soils follow fractionation patters that are similar to ${ }^{137} \mathrm{Cs}$, with a higher rate of accumulation in the residual soil fraction [9, 58-60]. The ${ }^{33} \mathrm{Cs}$ content can reach up to $94 \%$ of the total ${ }^{137} \mathrm{Cs}$ in the soils that were exposed to radiocesium contamination from the FDNPP accident [61]. The effects of elapsed time following the contamination of soils with ${ }^{137} \mathrm{Cs}$ were observed during our study of the ${ }^{133} \mathrm{Cs}$ contaminated samples $[9,59,62]$. The lower hydration energies of the ionic cesium resulted 
in the augmented occurrence of cesium in the interlayer or frayed edge sites of the soil particles [45-47]. In addition, the incorporation of radiocesium or stable cesium species in the most persistent fraction in the soil solid phases increased.

The kinetics of cesium sorption and the apparent reversibility of the sorption processes are intra-related. These processes are influenced by the slow sorption kinetics, competing cation characteristics, or both $[63,64]$. Thus, it was assumed that cesium migrates slowly to energetically favorable interlayer sites. Once the cesium reaches these sites, it is not easily released [64, 65]. Based on the above discussion and the "three-box" model that was proposed by Comans and Hockley [65], a schematic diagram (as illustrated in Figure 5) was used to summarize the temporal variations of the Cs accumulation patterns in the soils after uncharacteristic exposure.

\subsection{Conclusions}

The distribution of $\mathrm{Cs}$ in soils that were exposed to ${ }^{133} \mathrm{Cs}$ (red clay, leaf-mold and andosol soils) was determined in different operationally defined physico-chemical and particle size fractions. A pseudo-uniformity in the Cs distribution was observed in the soil particle size fractions regardless of soil type. In addition, the red clay soil was more vulnerable to Cs during the uncharacteristic high-dose exposure. Greater soil organic matter contents resulted in lower Cs retention rates. Furthermore, the soil cation concentrations affected the rate of soil Cs uptake. The incorporation of Cs mainly occurred in the strongly bound fraction of the soil solid phase, and the temporal movement enhanced the content in the same fraction. Therefore, the long term Cs migration pattern indicated that the movement of the initially mobile Cs fraction relative to the irreversible soil core resulted in a Cs fraction that was less labile for soil-to-plant transfer.

\section{Acknowledgments}

This research was partially supported by the Grants-in-Aid for Scientific Research (24310056 and $25 \cdot 5863)$ from the Japan Society for the Promotion of Science. 


\section{References}

[1] A.V. Yablokov, V.B. Nesterenko, A.V. Nesterenko, Atmospheric, water, and soil contamination after Chernobyl, Ann. N. Y. Acad. Sci. 1181 (2009) 223-236.

[2] E.J. Bromet, J.M. Havenaar, L.T. Guey, A 25 year retrospective review of the psychological consequences of the chernobyl accident, Clin. Oncol. 23 (2011) 297305.

[3] T.M. Nakanishi, N.I. Kobayashi, K. Tanoi, Radioactive cesium deposition on rice, wheat, peach tree and soil after nuclear accident in Fukushima, J. Radioanal. Nucl. Ch. 296 (2013) 985-989.

[4] N. Yamaguchi, S. Eguchi, H. Fujiwara, K. Hayashi, H. Tsukada, Radiocesium and radioiodine in soil particles agitated by agricultural practices: Field observation after the Fukushima nuclear accident, Sci. Total Environ. 425 (2012) 128-134.

[5] K. Tanaka, Y. Takahashi, A. Sakaguchi, M. Umeo, S. Hayakawa, H. Tanida, T. Saito, Y. Kanai, Vertical profiles of Iodine-131 and Cesium-137 in soils in Fukushima Prefecture related to the Fukushima Daiichi Nuclear Power Station Accident, Geochem. J. 46 (2012) 73-76.

[6] T. Ohno, Y. Muramatsu, Y. Miura, K. Oda, N. Inagawa, H. Ogawa, A. Yamazaki, C. Toyama, M. Sato, Depth profiles of radioactive cesium and iodine released from the Fukushima Daiichi nuclear power plant in different agricultural fields and forests, Geochem. J. 46 (2012) 287-295.

[7] J. Koarashi, M. Atarashi-Andoh, T. Matsunaga, T. Sato, S. Nagao, H. Nagai, Factors affecting vertical distribution of Fukushima accident-derived radiocesium in soil under different land-use conditions, Sci. Total Environ. 431 (2012) 392-401.

[8] L.L. Cook, R.S. Inouye, T.P. McGonigle, G.J. White, The distribution of stable cesium in soils and plants of the eastern Snake River Plain in southern Idaho, J. Arid Environ. 69 (2007) 40-64.

[9] H. Tsukada, A. Takeda, S.i. Hisamatsu, J. Inaba, Concentration and specific activity of fallout ${ }^{137} \mathrm{Cs}$ in extracted and particle-size fractions of cultivated soils, J. Environ. Radioact. 99 (2008) 875-881.

[10] E. Smolders, H. Tsukada, The transfer of radiocesium from soil to plants: Mechanisms, data, and perspectives for potential countermeasures in Japan, Integr. Environ. Assess. Manag. 7 (2011) 379-381. 
[11] S. Staunton, On the mechanisms which determine the fate of radiocaesium in soil, Analusis 25 (1997) M24-M28.

[12] J. Hilton, R.S. Cambray, N. Green, Chemical fractionation of radioactive cesium in airborne particles containing bomb fallout, Chernobyl fallout and atmospheric material from the Sellafield site, J. Environ. Radioact. 15 (1992) 103-111.

[13] N. Yoshida, Y. Takahashi, Land-surface contamination by radionuclides from the Fukushima Daiichi nuclear power plant accident, Elements 8 (2012) 201-206.

[14] N. Victorova, O. Voitesekhovitch, B. Sorochinsky, H. Vandenhove, A. Konoplev, I. Konopleva, Phytoremediation of Chernobyl contaminated land, Radiat. Prot. Dosim. 92 (2000) 59-64.

[15] T.J. Yasunari, A. Stohl, R.S. Hayano, J.F. Burkhart, S. Eckhardt, T. Yasunari, Cesium-137 deposition and contamination of Japanese soils due to the Fukushima nuclear accident, P. Natl. Acad. Sci. USA 108 (2011) 19530-19534.

[16] M. Chino, H. Nakayama, H. Nagai, H. Terada, G. Katata, H. Yamazawa, Preliminary estimation of release amounts of ${ }^{131} \mathrm{I}$ and ${ }^{137} \mathrm{Cs}$ accidentally discharged from the Fukushima Daiichi nuclear power plant into the atmosphere, J. Nucl. Sci. Technol. 48 (2011) 1129-1134.

[17] Y. Morino, T. Ohara, M. Nishizawa, Atmospheric behavior, deposition, and budget of radioactive materials from the Fukushima Daiichi nuclear power plant in March 2011, Geophys. Res. Lett. 38 (2011) L00G11.

[18] P.J. White, M.R. Broadley, Mechanisms of caesium uptake by plants, New Phytol. 147 (2000) 241-256.

[19] P. Porto, D.E. Walling, V. Ferro, Validating the use of caesium-137 measurements to estimate soil erosion rates in a small drainage basin in Calabria, Southern Italy, Journal of Hydrology 248 (2001) 93-108.

[20] P. Porto, D.E. Walling, V. Tamburino, G. Callegari, Relating caesium-137 and soil loss from cultivated land, CATENA 53 (2003) 303-326.

[21] P. Varskog, R. Næumann, E. Steinnes, Mobility and plant availability of radioactive Cs in natural soil in relation to stable Cs, other alkali elements and soil fertility, J. Environ. Radioact. 22 (1994) 43-53.

[22] H. Tsukada, H. Hasegawa, S. Hisamatsu, S. Yamasaki, Transfer of ${ }^{137}$ Cs and stable Cs from paddy soil to polished rice in Aomori, Japan, J. Environ. Radioact. 59 (2002) $351-363$. 
[23] H. Tsukada, H. Hasegawa, Soil-to-plant transfer of 137Cs and other essential and trace elements in cabbage plants, J. Radioanal. Nucl. Ch. 252 (2002) 219-224.

[24] H. Tsukada, H. Shibata, H. Sugiyama, Transfer of radiocaesium and stable caesium from substrata to mushrooms in a pine forest in Rokkasho-mura, Aomori, Japan, J. Environ. Radioact. 39 (1998) 149-160.

[25] W. Rühm, S. Yoshida, Y. Muramatsu, M. Steiner, E. Wirth, Distribution patterns for stable ${ }^{133} \mathrm{Cs}$ and their implications with respect to the long-term fate of radioactive ${ }^{134} \mathrm{Cs}$ and ${ }^{137} \mathrm{Cs}$ in a semi-natural ecosystem, J. Environ. Radioact. 45 (1999) 253-270.

[26] H. Tsukada, Y. Nakamura, Transfer of ${ }^{137} \mathrm{Cs}$ and stable Cs from soil to potato in agricultural fields, Sci. Total Environ. 228 (1999) 111-120.

[27] H. Tsukada, H. Hasegawa, S. Hisamatsu, S. Yamasaki, Rice uptake and distributions of radioactive ${ }^{137} \mathrm{Cs}$, stable ${ }^{133} \mathrm{Cs}$ and $\mathrm{K}$ from soil, Environ. Pollut. 117 (2002) 403409.

[28] H. Tsukada, A. Takeda, T. Takahashi, H. Hasegawa, S.i. Hisamatsu, J. Inaba, Uptake and distribution of ${ }^{90} \mathrm{Sr}$ and stable $\mathrm{Sr}$ in rice plants, J. Environ. Radioact. 81 (2005) 221-231.

[29] BSI, Code of Practice for Earthworks, British Standards Institution (BSI), London, 2009.

[30] A. Tessier, P.G.C. Campbell, M. Bisson, Sequential extraction procedure for the speciation of particulate trace metals, Anal. Chem. 51 (1979) 844-851.

[31] I. Maiz, I. Arambarri, R. Garcia, E. Millán, Evaluation of heavy metal availability in polluted soils by two sequential extraction procedures using factor analysis, Environ. Pollut. 110 (2000) 3-9.

[32] Z.A. Begum, I.M.M. Rahman, H. Sawai, S. Mizutani, T. Maki, H. Hasegawa, Effect of extraction variables on the biodegradable chelant-assisted removal of toxic metals from artificially contaminated European reference soils, Water Air Soil Poll. 224 (2013) 1381.

[33] P. Spezzano, Distribution of pre- and post-Chernobyl radiocaesium with particle size fractions of soils, J. Environ. Radioact. 83 (2005) 117-127.

[34] F.R. Livens, M.S. Baxter, Particle size and radionuclide levels in some west Cumbrian soils, Sci. Total Environ. 70 (1988) 1-17. 
[35] J.P. Absalom, S.D. Young, N.M.J. Crout, Radio-caesium fixation dynamics: Measurement in six Cumbrian soils, Eur. J. Soil Sci. 46 (1995) 461-469.

[36] Q. He, D.E. Walling, Interpreting particle size effects in the adsorption of ${ }^{137} \mathrm{Cs}$ and unsupported ${ }^{210} \mathrm{~Pb}$ by mineral soils and sediments, J. Environ. Radioact. 30 (1996) 117-137.

[37] P. Porto, D.E. Walling, Validating the use of ${ }^{137} \mathrm{Cs}$ and ${ }^{210} \mathrm{~Pb}_{\mathrm{ex}}$ measurements to estimate rates of soil loss from cultivated land in southern Italy, J. Environ. Radioact. 106 (2012) 47-57.

[38] P. Porto, D.E. Walling, Using plot experiments to test the validity of mass balance models employed to estimate soil redistribution rates from ${ }^{137} \mathrm{Cs}$ and ${ }^{210} \mathrm{~Pb}_{\mathrm{ex}}$ measurements, Appl. Radiat. Isot. 70 (2012) 2451-2459.

[39] P. Porto, D.E. Walling, V. Ferro, C. di Stefano, Validating erosion rate estimates provided by caesium-137 measurements for two small forested catchments in Calabria, southern Italy, Land Degrad. Dev. 14 (2003) 389-408.

[40] S. Staunton, C. Dumat, A. Zsolnay, Possible role of organic matter in radiocaesium adsorption in soils, J. Environ. Radioact. 58 (2002) 163-173.

[41] Y. Nakamaru, N. Ishikawa, K. Tagami, S. Uchida, Role of soil organic matter in the mobility of radiocesium in agricultural soils common in Japan, Colloids and Surfaces A: Physicochemical and Engineering Aspects 306 (2007) 111-117.

[42] J.T. Smith, R.N.J. Comans, Modelling the diffusive transport and remobilisation of ${ }^{137} \mathrm{Cs}$ in sediments: The effects of sorption kinetics and reversibility, Geochim. Cosmochim. Ac. 60 (1996) 995-1004.

[43] Y. Kim, R.J. Kirkpatrick, ${ }^{23} \mathrm{Na}$ and ${ }^{133} \mathrm{Cs}$ NMR study of cation adsorption on mineral surfaces: local environments, dynamics, and effects of mixed cations, Geochim. Cosmochim. Ac. 61 (1997) 5199-5208.

[44] B.L. Sawhney, Selective sorption and fixation of cations by clay minerals: A review, Clays Clay Miner. 20 (1972) 93-100.

[45] N.T. Coleman, D. Craig, R.J. Lewis, Ion-exchange reactions of cesium, Soil Sci. Soc. Am. J. 27 (1963) 287-289.

[46] B.L. Sawhney, Sorption and fixation of microquantities of cesium by clay minerals: Effect of saturating cations, Soil Sci. Soc. Am. J. 28 (1964) 183-186.

[47] B.L. Sawhney, Sorption of cesium from dilute solutions, Soil Sci. Soc. Am. J. 29 (1965) 25-28. 
[48] V.C. Farmer, M.J. Wilson, Experimental conversion of biotite to hydrobiotite, Nature 226 (1970) 841-842.

[49] J.Q. Jiang, N.J.D. Graham, Enhanced coagulation using Al/Fe(III) coagulants: Effect of coagulant chemistry on the removal of colour-causing NOM, Environ. Technol. 17 (1996) 937-950.

[50] A. Barona, I. Aranguiz, A. Elías, Metal associations in soils before and after EDTA extractive decontamination: Implications for the effectiveness of further clean-up procedures, Environ. Pollut. 113 (2001) 79-85.

[51] M.C. Steele, J. Pichtel, Ex-situ remediation of a metal-contaminated superfund soil using selective extractants, J. Environ. Eng.-ASCE 124 (1998) 639-645.

[52] S. Tandy, K. Bossart, R. Mueller, J. Ritschel, L. Hauser, R. Schulin, B. Nowack, Extraction of heavy metals from soils using biodegradable chelating agents, Environ. Sci. Technol. 38 (2004) 937-944.

[53] Z.A. Begum, I.M.M. Rahman, Y. Tate, H. Sawai, T. Maki, H. Hasegawa, Remediation of toxic metal contaminated soil by washing with biodegradable aminopolycarboxylate chelants, Chemosphere 87 (2012) 1161-1170.

[54] C.L. Dahlin, C.A. Williamson, W. Keith Collins, D.C. Dahlin, Sequential extraction versus comprehensive characterization of heavy metal species in Brownfield soils, Environ Forensics 3 (2002) 191-201.

[55] G. Dermont, M. Bergeron, G. Mercier, M. Richer-Laflèche, Metal-contaminated soils: Remediation practices and treatment technologies, Pract. Period. Hazard. Toxic Radioact. Waste Manage. 12 (2008) 188-209.

[56] G. Dermont, M. Bergeron, G. Mercier, M. Richer-Laflèche, Soil washing for metal removal: A review of physical/chemical technologies and field applications, J. Hazard. Mater. 152 (2008) 1-31.

[57] G. Dermont, M. Bergeron, M. Richer-Laflèche, G. Mercier, Remediation of metalcontaminated urban soil using flotation technique, Sci. Total Environ. 408 (2010) 1199-1211.

[58] D.H. Oughton, B. Salbu, G. Riise, H. Lien, G. Ostby, A. Noren, Radionuclide mobility and bioavailability in Norwegian and Soviet soils, Analyst 117 (1992) 481486. 
[59] A. Rigol, M. Roig, M. Vidal, G. Rauret, Sequential extractions for the study of radiocesium and radiostrontium dynamics in mineral and organic soils from Western Europe and Chernobyl areas, Environ. Sci. Technol. 33 (1999) 887-895.

[60] S. Forsberg, M. Strandmark, Migration and chemical availability of ${ }^{137} \mathrm{Cs}$ and ${ }^{90} \mathrm{Sr}$ in Swedish long-term experimental pastures, Water Air Soil Pollut 127 (2001) 157-171.

[61] H.B. Qin, Y. Yokoyama, Q.H. Fan, H. Iwatani, K. Tanaka, A. Sakaguchi, Y. Kanai, J.M. Zhu, Y. Onda, Y. Takahashi, Investigation of cesium adsorption on soil and sediment samples from Fukushima Prefecture by sequential extraction and EXAFS technique, Geochem. J. 46 (2012) 297-302.

[62] K. Rosén, C.A. Shand, E. Haak, M.V. Cheshire, Effect of clay content and wettingand-drying on radiocaesium behaviour in a peat and a peaty podzol, Sci. Total Environ. 368 (2006) 795-803.

[63] D.W. Evans, J.J. Alberts, R.A. Clark Iii, Reversible ion-exchange fixation of cesium137 leading to mobilization from reservoir sediments, Geochim. Cosmochim. Ac. 47 (1983) 1041-1049.

[64] R.N.J. Comans, M. Haller, P. De Preter, Sorption of cesium on illite: Non-equilibrium behaviour and reversibility, Geochim. Cosmochim. Ac. 55 (1991) 433-440.

[65] R.N.J. Comans, D.E. Hockley, Kinetics of cesium sorption on illite, Geochim. Cosmochim. Ac. 56 (1992) 1157-1164. 
Table 1: Chemical interpretation and the extraction conditions of the protocol that was used for fractionating the solid phase cesium from the soil

\begin{tabular}{|c|c|c|c|c|c|}
\hline \multirow[t]{3}{*}{ Fraction } & \multirow{3}{*}{$\begin{array}{l}\text { Chemical } \\
\text { interpretation }\end{array}$} & \multicolumn{4}{|l|}{ Extraction conditions (for $0.25 \mathrm{~g}$ soil) } \\
\hline & & \multirow[t]{2}{*}{ Extractants and other conditions } & Duration & Temp. & \multirow{2}{*}{ Agitation } \\
\hline & & & $\mathrm{h}$ & ${ }^{\circ} \mathrm{C}$ & \\
\hline F1 & Exchangeable & $1 \mathrm{M} \mathrm{MgCl}_{2}(\mathrm{pH} 7 ; 4 \mathrm{~mL})$ & 1 & $25 \pm 2$ & continuous \\
\hline $\mathrm{F} 2$ & Acid soluble $^{a}$ & $1 \mathrm{M} \mathrm{NaOAc}$ (pH 5, adjusted with acetic acid; $4 \mathrm{~mL}$ ) & 5 & $25 \pm 2$ & continuous \\
\hline F3 & Reducible $^{a}$ & $0.04 \mathrm{M} \mathrm{NH}_{2} \mathrm{OH} \cdot \mathrm{HCl}$ in $25 \%(\mathrm{v} / \mathrm{v})$ acetic acid $(10 \mathrm{~mL})$ & 6 & $96 \pm 3$ & occasional \\
\hline \multirow[t]{3}{*}{$\mathrm{F} 4$} & Oxidisable $^{a}$ & $\begin{array}{l}0.02 \mathrm{M} \mathrm{HNO}_{3}(3 \mathrm{~mL})+30 \% \mathrm{H}_{2} \mathrm{O}_{2}(\mathrm{pH} 2 \text {, adjusted } \\
\left.\text { with } \mathrm{HNO}_{3} ; 2.5 \mathrm{~mL}\right)\end{array}$ & 2 & $85 \pm 3$ & occasional \\
\hline & & $30 \% \mathrm{H}_{2} \mathrm{O}_{2}\left(\mathrm{pH} 2\right.$, adjusted with $\left.\mathrm{HNO}_{3} ; 1.5 \mathrm{~mL}\right)$ & 3 & $85 \pm 3$ & intermittent \\
\hline & & $3.2 \mathrm{M} \mathrm{NH}_{4} \mathrm{OAc}$ in $20 \%(\mathrm{v} / \mathrm{v}) \mathrm{HNO}_{3}(2.5 \mathrm{~mL})$ & 0.5 & $85 \pm 3$ & continuous \\
\hline F5 & Residual & Microwave-assisted acid decomposition ${ }^{b}$ & - & - & - \\
\hline
\end{tabular}

$\overline{{ }^{a}}$ The fraction names 'acid-soluble', 'reducible' and 'oxidisable' were originally called 'bound to carbonates', 'bound to iron and manganese oxides' and 'bound to the organic matter' by Tessier, et al. [30].

${ }^{b}$ The detailed microwave-assisted acid decomposition procedure for determining the soil cesium contents is available in Section 2.3.5. 
Raw Soil Cs-Spiked Soil
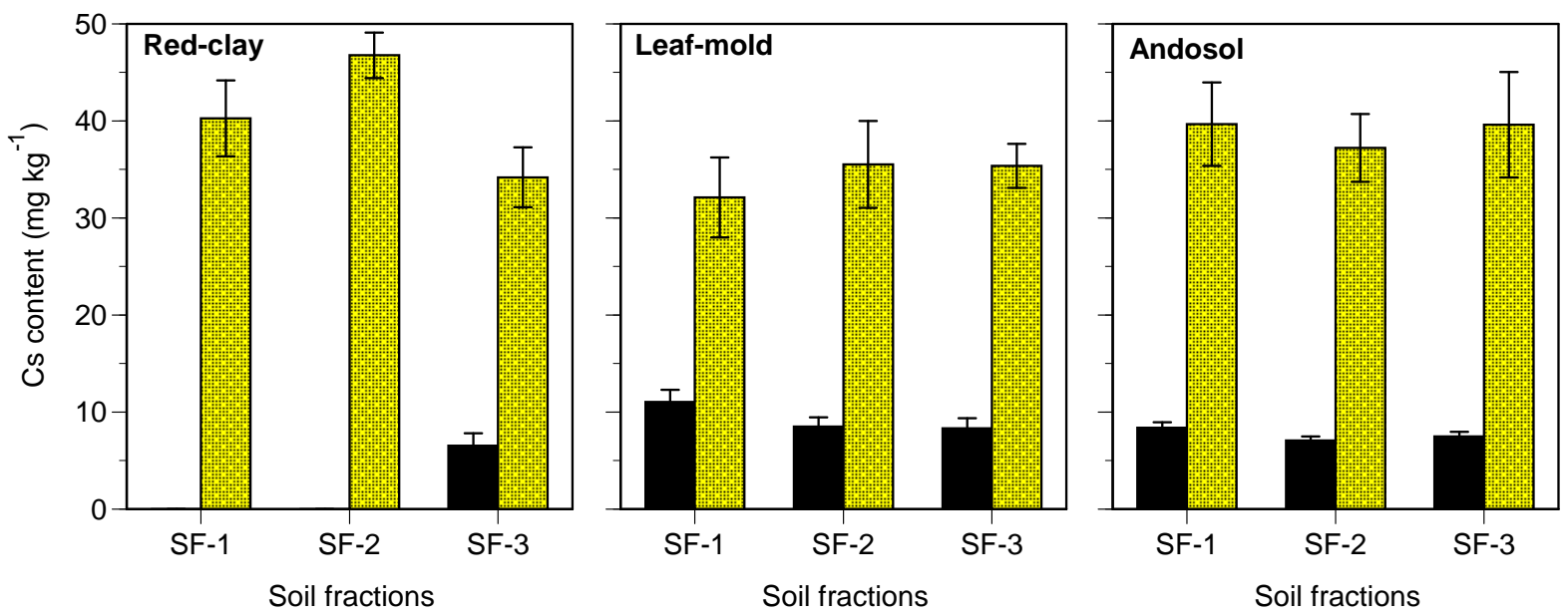

Figure 1: Cesium concentrations in the raw and cesium-spiked soils $(n=3)$. SF-1: Size fraction of 2000-212 $\mu \mathrm{m}$ (coarse sand); SF-2: Size fraction of 212-63 $\mu \mathrm{m}$ (fine sand); and SF-3: Size fraction of $<63 \mu \mathrm{m}$ (silt and clay). 
(a)

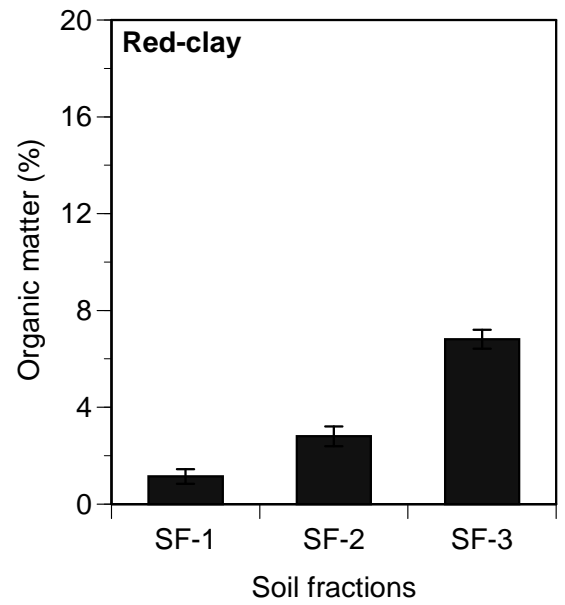

(b)

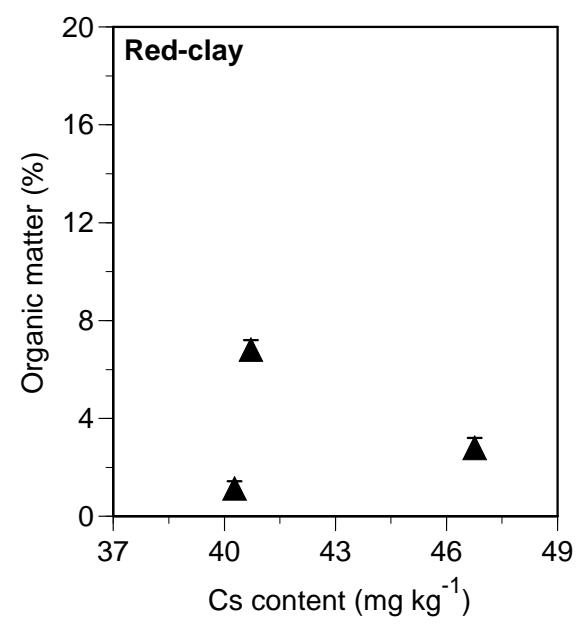

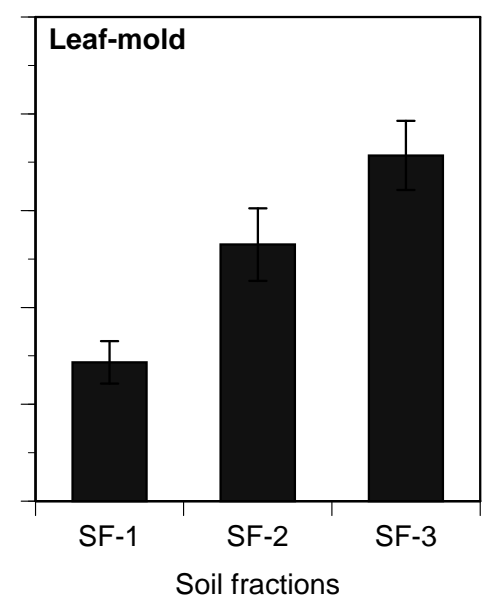
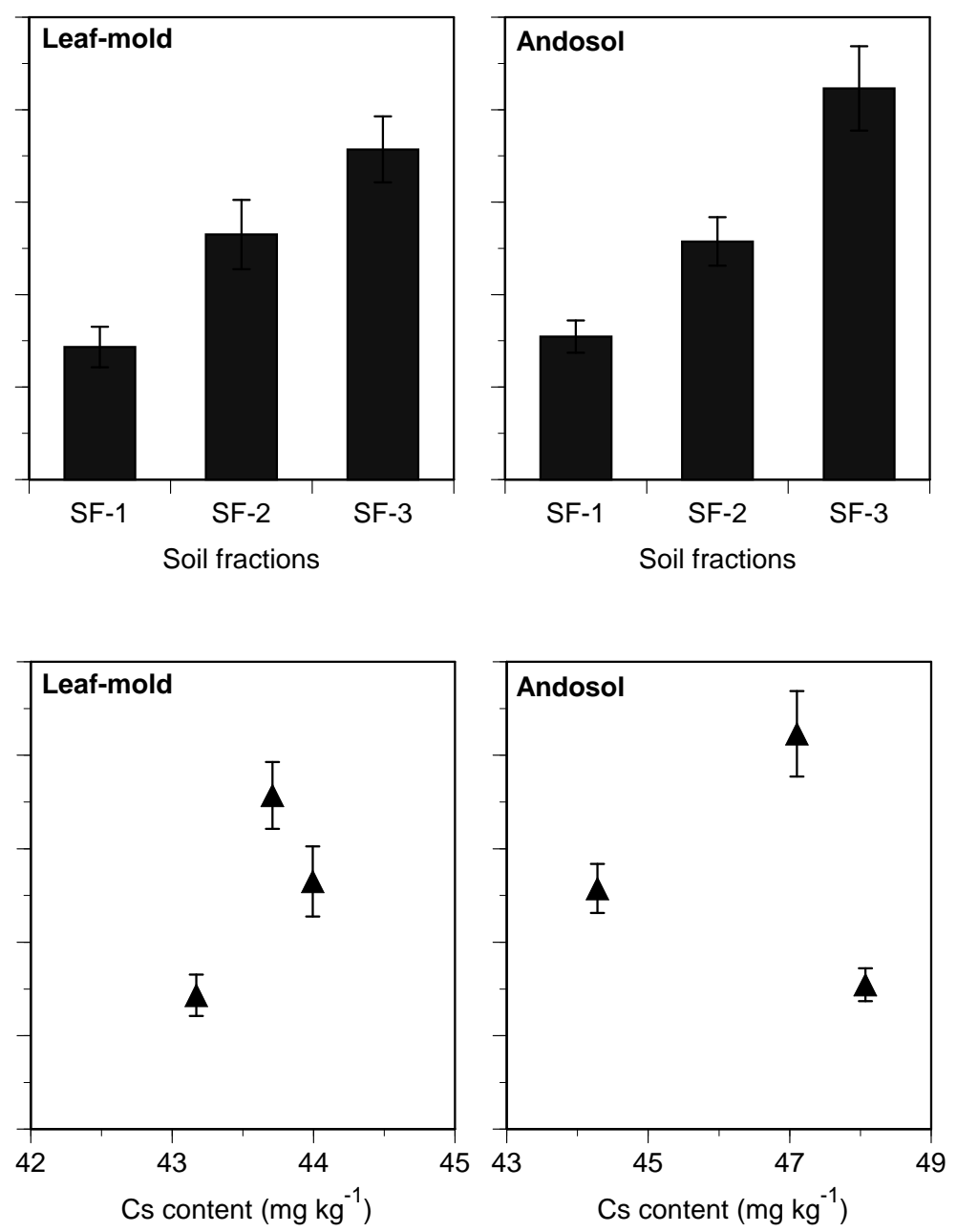

Figure 2: (a) The distribution patterns of the organic matter contents in the soils. (b) The correlation between the cesium accumulation pattern and the organic matter contents in the soils $(n=3)$. SF-1: Size fraction of 2000-212 $\mu \mathrm{m}$ (coarse sand); SF-2: Size fraction of 212$63 \mu \mathrm{m}$ (fine sand); and SF-3: Size fractions of $<63 \mu \mathrm{m}$ (silt and clay). 


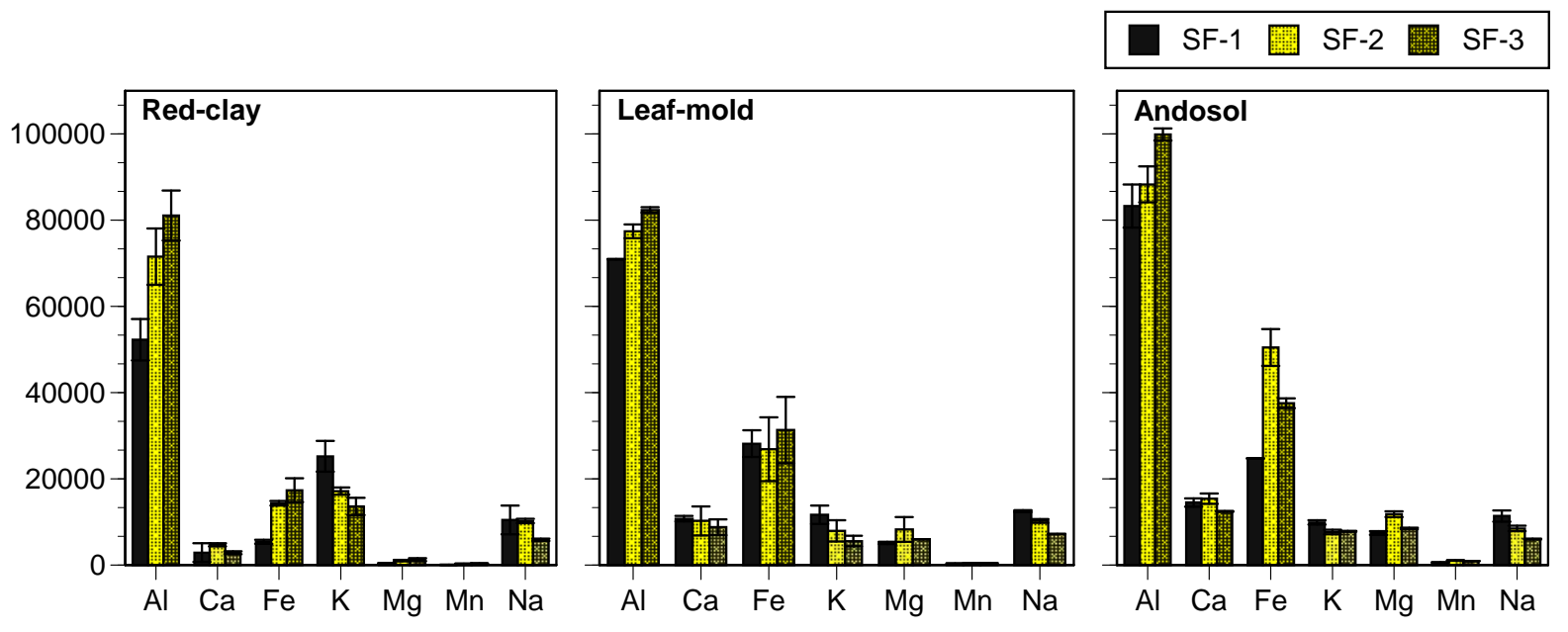

Figure 3: The distribution pattern of the coexisting soil cations $(n=3)$. SF-1: Size fraction of 2000-212 $\mu \mathrm{m}$ (coarse sand); SF-2: Size fraction of 212-63 $\mu \mathrm{m}$ (fine sand); SF-3: and Size fraction of $<63 \mu \mathrm{m}$ (silt and clay). 
(a)

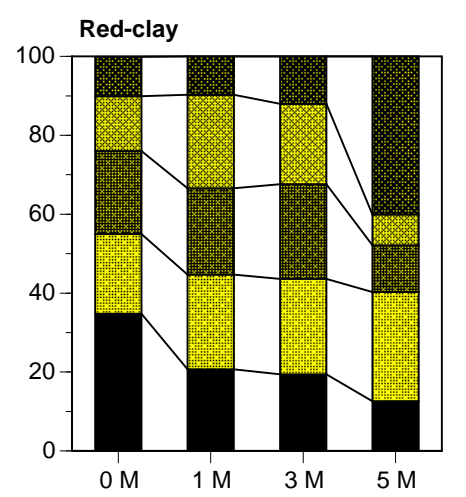

(b)-I

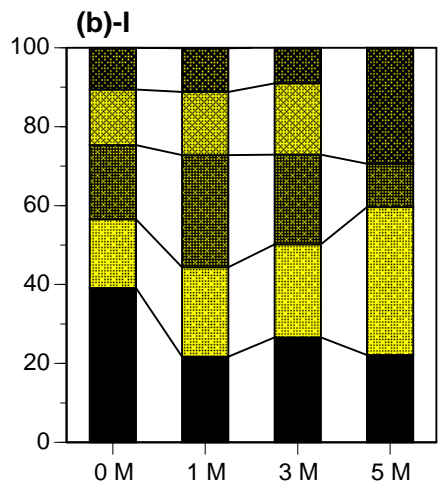

(b)-II

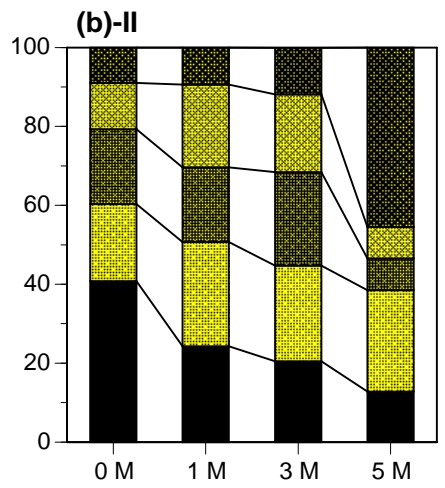

(b)-III

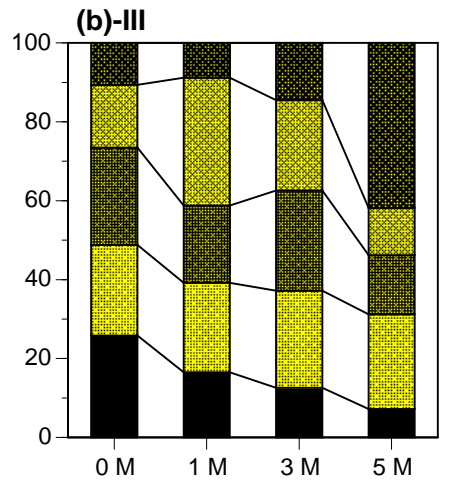

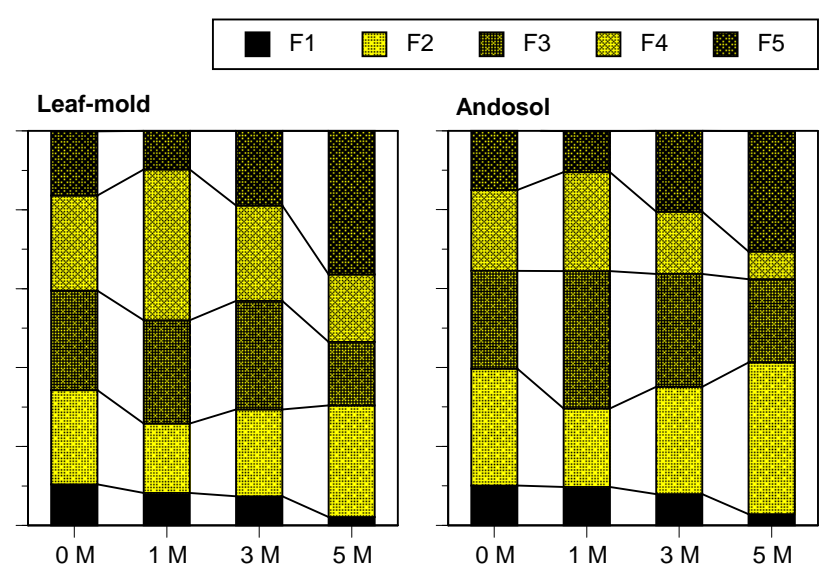
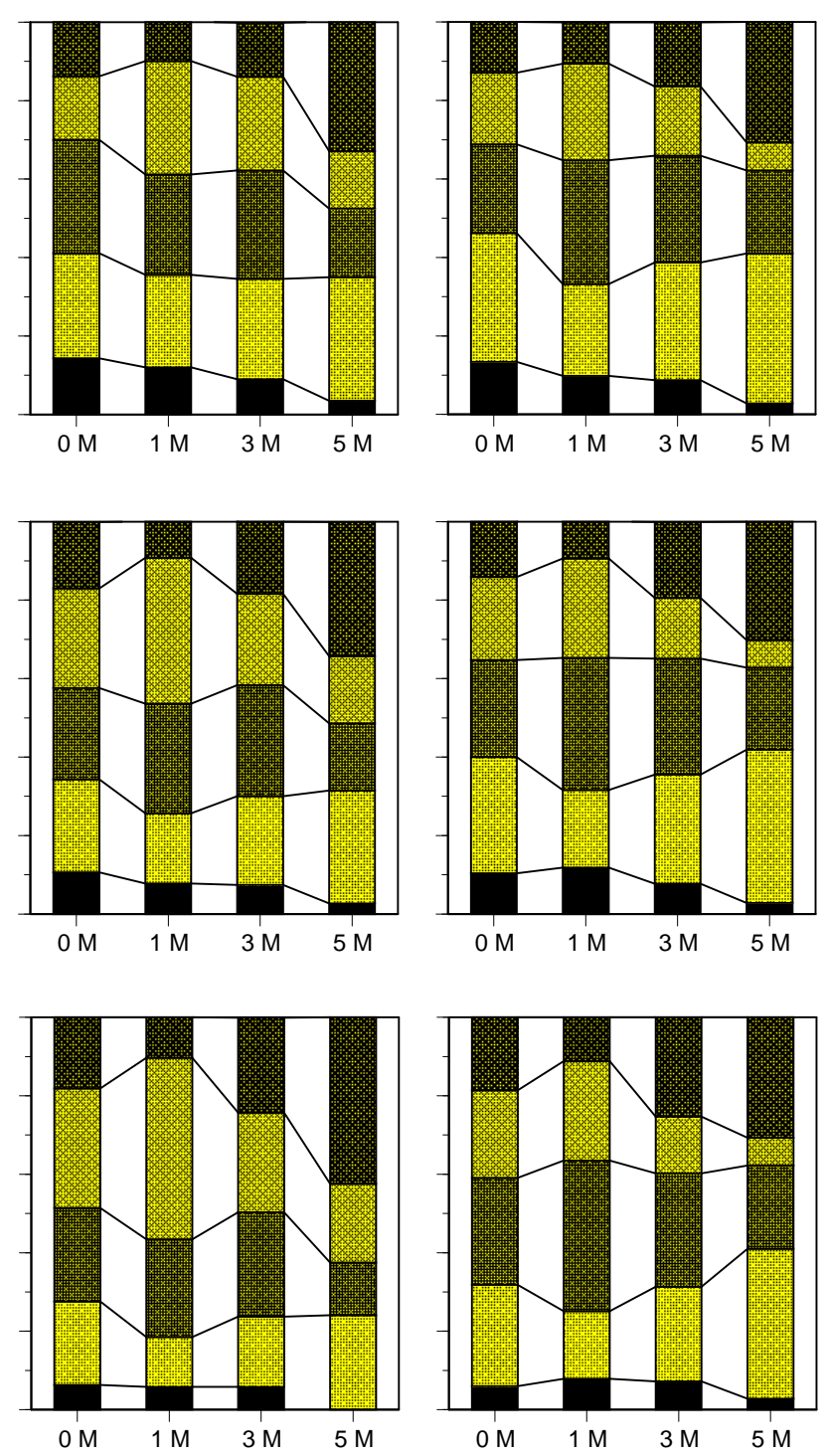

Figure 4: Comparative temporal distribution of cesium in the soil solid-phases: (a) without size fractionation, (b-I) size fraction of 2000-212 $\mu \mathrm{m}$ (coarse sand), (b-II) size fraction of 212-63 $\mu \mathrm{m}$ (fine sand), and (b-III) size fraction of $<63 \mu \mathrm{m}$ (silt and clay). F1: Exchangeable, F2: Acid soluble, F3: Reducible, F4: Oxidisable, and F5: Residual. 

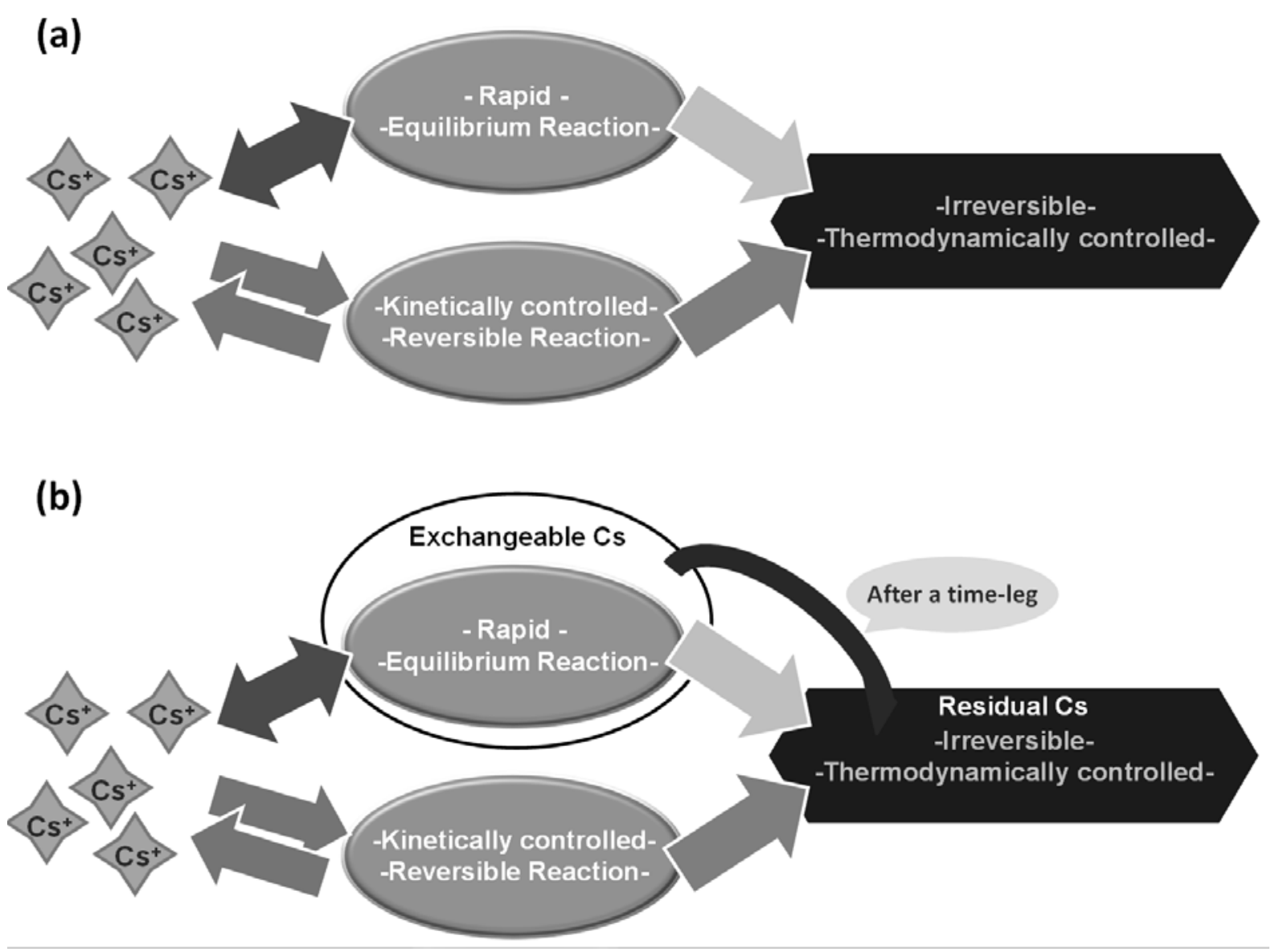

Figure 5: A schematic model of (a) the instantaneous Cs-sorption patterns in the soils and (b) the temporal changes of the Cs-sorption patterns in the soils. 